\title{
\#MeToo and Female Patients with Major Mental Disorders: What Should Academic Psychiatry Do?
}

\author{
John Coverdale ${ }^{1} \cdot$ Laura Weiss Roberts ${ }^{2} \cdot$ Richard Balon $^{3} \cdot$ Eugene V. Beresin ${ }^{4} \cdot$ Anthony P. S. Guerrero $^{5}$. \\ Alan K. Louie ${ }^{2} \cdot$ Rashi Aggarwal $^{6} \cdot$ Mary K. Morreale $^{3} \cdot$ Adam M. Brenner $^{7}$
}

Received: 2 October 2019 / Accepted: 9 October 2019 / Published online: 29 October 2019

(C) Academic Psychiatry 2019

If it is hard for privileged women to come forward, we have to acknowledge how much harder it is for women who are marginalized to be believed.

- Carolyn M. West (New York Times, September 23, 2018) [1]

\#MeToo is an international movement that was founded in 2006. The movement aims to reframe and expand the conversation around sexual violence, to provide assistance to providers, to hold perpetrators accountable, and to create solutions to interrupt sexual violence in communities [2]. Sexual violence against women and girls is a global problem [3], and the \#MeToo movement brings much needed light to the plight of victims and to the pervasiveness of sexual violence. Sexual violence takes many forms by perpetrators both male and female, including unwanted sexual comments or acts; derogatory sexual language or threats; coercive sexual behavior such as harassment, stalking, and sexual assault or rape; forced or early marriage without consent; female genital mutilation;

John Coverdale

jhc@bcm.edu

1 Baylor College of Medicine, Houston, TX, USA

2 Stanford University, Stanford, CA, USA

3 Wayne State University, Detroit, MI, USA

4 Harvard Medical School, Boston, MA, USA

5 University of Hawai'i John A. Burns School of Medicine, Honolulu, HI, USA

6 Rutgers New Jersey Medical School, Newark, NJ, USA

7 University of Texas Southwestern Medical Center, Dallas, TX, USA and sex trafficking. Sexual violence is a part of criminal wartime behavior experienced by some, and sexual violence is a part of everyday life experienced by many.

In this issue of Academic Psychiatry, Wainberg, McKinnon, and Cournos [4] assert the need for action in training psychiatric faculty and residents to discuss sexual well-being as a health care issue. At the time of writing, a search of PubMed using the term \#MeToo found 59 other articles, none of which directly addressed the plight of patients with major mental disorders. Nor have some influential publications on violence specifically identified these patients as a risk group [5, 6]. Moreover, personal accounts of sexual violence by women in the New York Times did not include women who identified as having psychiatric disorders [7,8], and direct representation of people with mental disorders tends to be limited in the media [9]. Consequently, the experiences of sexual violence and needs of patients with major mental disorders is surely poorly appreciated by the general public and policy makers as well as overlooked in previous medical publications concerning the \#MeToo movement. The \#MeToo website provides national resources for a wide spectrum of survivors but not specifically for women or men with major mental disorders [2].

In this editorial, we aim to rectify this imbalance, seeking to elevate the issues encountered by women living with mental illness. We will describe some of the research on sexual violence against adult women with major mental disorders and briefly discuss some of the potential responses to this public health issue. We recognize that men, men with major mental disorders, adults with cognitive and physical impairments, and children and adolescents constitute other very vulnerable groups who are also especially worthy of attention. Our focus for this editorial is limited to adult women with major mental disorders. By these methods, we hope to firmly entrench our patients into the \#MeToo conversation. 


\section{Sexual Violence Perpetrated Against Women with Major Mental Disorders}

Because trauma can be causative of psychiatric disorders, it is important to be clear about the direction of causality in research concerning sexual trauma and major mental disorders. Our interest for this editorial concerns the risk of sexual violence against patients with established major mental disorders. Studies that survey patients regarding whether or not they had been victims of sexual violence within a broad time frame of adulthood cannot clearly establish whether the patients were already diagnosed with serious mental disorders before becoming victims of sexual violence [10].

One recently conducted, and high-quality systematically conducted, review reported on 30 studies on recent violence by any perpetrator against people with serious mental disorders [11]. Within this review, eight studies reported on the prevalence of various forms of sexual violence against women within the previous year with a median prevalence rate of $10 \%$ [12-19]. Our own search found three additional studies [20-22].

Of these 11 studies, four were conducted in the USA [12, 13, 15, 20], two in Sweden [14, 18], two in Britain [16, 21], two in the Netherlands [17, 22], and one in Greece [19]. The study samples included predominantly patients with schizophrenia or other psychotic disorders and bipolar or depressive disorders, although one provided data on patients who were currently depressed [22]. Response rates were greater than $70 \%$ for six of the studies $[12-15,18,21]$, and six of the studies compared their data on sexual violence with comparison groups including the general population of individuals who were not mentally ill $[13,16,17,19,21,22]$. Ten of the studies $[12-19,20,21]$ assessed the rate of sexual violence over a 1-year period, with sexual violence usually being broadly defined, although two studies also provided data specifically about rape $[12,18]$. One study assessed patients in an urban emergency department who had presented with a chief complaint of sexual assault [20]. In this study, a major psychiatric diagnosis was found in $26 \%$ of the 819 women. These studies together found high rates of sexually violent acts perpetrated against women with major mental disorders [12-22]. Overall, people with major mental disorders were at greater risk of sexual violence than comparison groups who did not have major mental disorders [13, 16, 17, 19, 21, 22]. We did not find information on risks of becoming sexually trafficked among women with major mental disorders.

Although there is little information, risk factors associated with sexual victimization of persons with major mental disorders include homelessness, alcohol or substance abuse/misuse, and illness severity [23, 24]. Concomitant physical, intellectual, social, and interpersonal disabilities also pose significant risks for sexual assault. Women with mental health disorders who are at the mercy of caregivers or who are easily overpowered are more vulnerable to sexual abuse. Furthermore, in many instances, because of their cognitive or communication deficits, they are less likely to be able to report abuse.

It would be expected that violent acts against patients with major mental disorders would exacerbate their mental health problems. Depression, anxiety disorders, posttraumatic stress disorder, and alcohol and substance use are potential consequences of stressful adversities. In one of the studies [16], female victims with major mental disorders were more likely to report adverse psychological/social effects than those victims without a major mental disorder. In another study [20], assaults on women with a major psychiatric diagnosis were more violent and resulted in body trauma more frequently than assaults on women without a psychiatric diagnosis.

\section{Primary Prevention}

Homelessness was identified as one of the risk factors for sexual violence perpetrated against patients with major mental disorders $[23,24]$. Therefore, primary prevention, which is defined as preventing sexual violence from occurring, is supported by providing housing and shelters where women have safety and privacy with locked doors and security. Teaching social skills in the domains of finding and renting an apartment, using time well, getting closer to people, managing finances, avoiding drugs and alcohol problems, solving interpersonal problems, and managing one's health are proposed as an important determinant of housing acquisition and support [25]. The provision of stable housing for homeless adults with mental illness with intensive case management is also likely a cost-effective intervention in comparison with usual treatments [26].

Alcohol and substance use disorders have also been identified as risk factors [23, 24], and even when motivation for treatment is high, being homeless is associated with barriers to treatment [27]. Community outreach to substance users in community settings may be warranted. One helpful treatment model emphasized patient choice and housing over substance abuse treatment and did not penalize patients who refused treatment or relapsed on alcohol or drugs [28].

People living with mental illnesses should also receive educational resources and emotional support related to how best to avoid potentially dangerous circumstances. Financial support and a guaranteed income should be provided for individuals with disabilities so that they do not have to resort to risky behaviors such as exchanging sex for financial gain. Patients should also be taught key skills, such as how to resist unwanted advances and how to say no when feeling uncomfortable about offers for sex. Psychoeducation, problem-solving, and communications skills training are integral aspects of evidence-based cognitive-behavioral approaches for the 
treatment of major mental disorders [29]. Some patients with concomitant disabilities may not be amenable to psychoeducation or other means of individual primary prevention. In these cases, it is of the utmost importance to train, supervise, and sometimes monitor caregivers of the disabled to help prevent sexual assault.

There is a dearth of evidence-based sexual assault resistance programs for women with major mental disorders. One potential model, which was efficacious for university women in reducing sexual assaults, is the Enhanced, Assess, Acknowledge, Act, Sexual Assault Resistance Program [30]. This program consisted of four, 3-hour units of training, including (1) a focus on improving women's assessment of the risk of sexual assault by male acquaintances and developing problem-solving strategies to reduce perpetrator advantages, (2) assisting women to more quickly acknowledge the danger in situations that turned coercive, (3) providing instruction about and practice of effective options for resistance, including self-defense training, and (4) providing sexual information and strategies to explore sexual attitudes, values, and desires and to develop strategies for sexual communication. This program was also successful in reducing the occurrence of sexual assaults for women at higher risk because of previous rape victimization [30]. Police may be able to assist in skillsbased crime prevention programs [13].

\section{Secondary Prevention}

Secondary prevention, which concerns reducing the psychologically and physically distressing consequences of sexual violence, is mainly facilitated by routine screening in all clinical settings. Patients may be ashamed to report their abuse experiences or fear retaliation by perpetrators or even distrust their service providers. Thus, inquiry has to be handled with sensitivity to patients' cultural needs and vulnerabilities. Patients should be informed about the rationale for screening and about confidentiality safeguards. Most importantly, patients should be treated with dignity and respect as sensitive issues surrounding sexual violence and negative sexual experiences are explored. Psychiatrists should be mindful that questioning and physical assessments can further traumatize victims. Screening questions should also include the possibility that patients may be victims of sex trafficking [31].

Screening should also be supported by services that can adequately address identified problems and that can reduce psychological distress and improve the quality of life. Services should be integrated with emergency services, nursing, social work services, obstetrics and gynecology programs, and sexual health. One model of a secondary prevention clinic program for female survivors of sexual violence, although not necessarily for those with major mental disorders, partnered obstetrics-gynecology with psychiatry in attempting to address the longer term sequela of sexual violence in a trauma-informed setting [32]. Screening for the physical consequences of sexual assault and prophylaxis of sexually transmitted infections and unwanted pregnancies should occur according to established guidelines [33, 34] with accommodations for the special needs of patients with major mental disorders, including assisting patients who have paranoia during the physical examination. The psychologically distressing consequences of sexual violence should also be formally identified, assessed, and treated.

Training should be provided in order to assist the clinicians most likely to work with this population in identifying and managing traumatized patients. The training especially should address barriers to screening, because occasions of sexual violence are sometimes not recognized by mental health clinicians [35], and address how to manage effectively the physical and psychological consequences of sexually violent acts or to refer to others when indicated. Some may view inquiry about violence as not a part of their role [36]. Potential barriers to sexual history-taking include a view that patients with chronic psychiatric illness are much the same as others when it comes to risky sexual behaviors, a lack of knowledge on how to educate patients, and discomfort in discussing sexual topics [37]. Although a trauma policy and training program improved staff response to abuse disclosures in New Zealand outpatient mental health clinic settings, the proportion referred for relevant treatment remained low across abuse categories [38]. For adult women with major mental disorders and concomitant developmental disabilities in which screening may not be feasible or realistic, it is critical for caregivers to be attentive to the many causes of behavioral changes, such as agitation, depression, or diminished cognitive and communication capacities. In addition, primary care physicians, allied health professionals, family members, and caregivers who know patients well should be trained to observe behavioral changes that may herald sexual assault.

The police and the legal profession have especially valuable contributions to make. The police may be the first to learn about sexual assaults, and they organize referrals for support and treatment [33]. Because even articulate and capable women who do not have a mental disorder can experience great difficulties in negotiating the forensic and legal systems to seek redress [39], it is especially important to see that these systems are optimized to accommodate patients with major mental disorders who become victims of violence. Many individuals may find that dealing with the forensic implications of their experiences with sexual violence represent, psychologically, a "second rape" [40], and for this reason, services should be provided longitudinally. Psychiatry has an important role in ensuring that this is so and in supporting patients through these systems.

There is an emotional cost to bear when caring for patients who experience trauma. Work-related support [41] and 
interventions to reduce burnout [42] are important protective factors in the development of stress reactions. Organizations and their leadership will likely be financially advantaged by investing in well-being programs [43].

\section{Advocacy}

Services should be adequately funded to support female patients with major mental disorders who have been victims of violence. Such services include providing training to those most likely to work with this population on effectively identifying and managing patients who have experienced trauma, developing clinically integrated teams, and reaching out to community resources including the law enforcement and legal professions, providing women with social and financial supports and resources when indicated including sanctuaries, addressing safety in the areas where patients reside, and addressing poverty and homelessness. A broad approach also includes researching the efficacy of training programs and evaluating the potential benefits and harms of treatment including human trafficking programs. We also need to develop the evidence base on the prevalence of sexual violence, risks, and their mitigation. In order to achieve these goals, administrators and funders should appreciate the special vulnerabilities of women with major mental disorders and their risks to becoming victims of violence. And we should confront the pervasive cultural mechanisms that stigmatize and discriminate against patients with mental disorders and that subvert funding and support.

\section{Conclusion}

The \#MeToo movement has galvanized attention to sexual violence and to its solutions. Female patients with major mental disorders constitute an especially vulnerable population at risk of sexual violence. Women living with mental illness thoroughly deserve to be well represented in the \#MeToo conversations. The profession of psychiatry and indeed all disciplines who care for adult women with mental illnesses have critical roles to play in developing comprehensive primary and secondary preventive strategies and programs for which our patients are especially worthy. We should advocate for the services and research that protect and promote their interests and for education, especially of our trainees. The horror of sexual violence in all of its forms should drive our commitment to this end.

\section{Compliance with ethical standards}

Disclosure On behalf of all authors, the corresponding author states that there are no conflicts of interest.

\section{References}

1. Forten J. \#WhyIDidn'tReport: survivors of sexual assault share their stories after Trump Tweet. New York Times, September 23, 2018. Available at https://www.nytimes.com/2018/09/23/us/whyi-didnt-report-assault-stories.html. Last accessed 08/17/2019.

2. Me Too. MeToo. Available at https://metoomvmt.org. Last accessed 17 August 2019.

3. García-Moreno C, Zimmerman C, Morris-Gehring A, et al. Addressing violence against women: a call to action. Lancet. 2015;385:1685-95.

4. Wainberg ML, McKinnon K, Cournos F. Learning from \#MeToo: a call to action in the training of psychiatric faculty and residents to discuss sexuality as a health and mental health issue. Acad Psychiatry. 2019. https://doi.org/10.1007/s40596-019-01051-9.

5. Committee on Health Care for Underserved Women. Committee Opinion No. 516: Health care systems for underserved women. Obstet Gynecol. 2012;119:206-9.

6. Sumner SA, Mercy JA, Dahlberg LL, et al. Violence in the United States: status, challenges, and opportunities. JAMA. 2015;314: 478-88.

7. Polley S, Aronowitz NW, Baker KJM, MacKinnon CA, Marche S, et al. "This moment turned out to be fleeting": nine reflections on \#MeToo one year on. New York Times, October 6, 2018. Available at https://www.nytimes.com/2018/10/06/opinion/me-tooweinstein-one-year.html. Accessed 30 September 2019.

8. Wang V. How 7 women helped put sexual harassment on New York's Agenda. New York Times, February 12, 2019. Available at https://www.nytimes.com/2019/02/12/nyregion/sexualharassment-ny-legislature.html. Accessed 30 September 2019.

9. Nairn RG, Coverdale JH. People never see us living well: an appraisal of the personal stories about mental illness in a prospective print medial sample. Aust N Z J Psychiatry. 2005;39:281-7.

10. Coverdale JH, Turbott SH. Sexual and physical abuse of chronically ill psychiatric outpatients compared with a matched sample of medical outpatients. J Nerv Ment Dis. 2000;188:440-5.

11. Khalifeh H, Oram S, Osborn D, et al. Recent physical and sexual violence against adults with severe mental illness: a systematic review and meta-analysis. Int Rev Psychiatry. 2016;28:433-51.

12. Goodman LA, Salyers MP, Mueser KT, et al. Recent victimization in women and men with severe mental illness: prevalence and correlates. J Trauma Stress. 2001;14:615-32.

13. Teplin LA, McClellan GM, Abram KM, Weiner DA. Crime victimization in adults with severe mental illness: comparison with the National Crime Victimization Survey. Arch Gen Psychiatry. 2005;62:911-21.

14. Bengtsson-Tops A, Markström U, Lewin B. The prevalence of abuse in Swedish female psychiatric users, the perpetrators and places where abuse occurred. Nord J Psychiatry. 2005;59:504-10.

15. Chang JC, Cluss PA, Burke JG, et al. Partner violence screening in mental health. Gen Hosp Psychiatry. 2011;33:58-65.

16. Khalifeh H, Moran P, Borschmann R, et al. Domestic and sexual violence against patients with severe mental illness. Psychol Med. 2015;45:875-86.

17. Kamperman AM, Henrichs J, Bogaerts S, et al. Criminal victimisation in people with severe mental illness: a multi-site prevalence and incidence survey in the Netherlands. PLoS One. 2014;9(3):e91029.

18. Bengtsson A, Ehliasson K. Victimization in individuals suffering from psychosis: a Swedish cross-sectional study. J Psychiatr Ment Health Nurs. 2012;19:23-30.

19. Katsikidou M, Samakouri M, Fotiadou M, et al. Victimization of the severely mentally ill in Greece: the extent of the problem. Int J Social Psychiatry. 2013;59:706-15. 
20. Eckert LO, Sugar N, Fine D. Characteristics of sexual assault in women with a major psychiatric diagnosis. Am J Obstet Gynecol. 2002;186:1284-8 discussion 1288-91.

21. Khalifeh H, Oram S, Trevillion K, et al. Recent intimate partner violence among people with chronic mental illness: findings from a national cross-sectional survey. Br J Psychiatry. 2015;207:207-12.

22. Christ $\mathrm{C}$, de Jonge $\mathrm{M}$, Bockting CLH, et al. Prevalence and predictors of violent victimization in remitted patients with recurrent depression. J Affect Disord. 2018;238:405-11.

23. Maniglio R. Severe mental illness and criminal victimization: a systematic review. Acta Psychiatr Scand. 2009;119:180-91.

24. De Vries B, van Busschbach JT, van der Stouwe ECD, et al. Prevalence rate and risk factors of victimization in adult patients with a psychotic disorder: a systematic review and meta-analysis. Schizophr Bull. 2019;45:114-26.

25. Gabrielian S, Hamilton AB, Gelberg L, et al. Identifying social skills that support housing attainment and retention among homeless persons with serious mental illness. Psychiatr Serv. 2019;70: 374-80.

26. Latimer EA, Rabouin D, Cao Z, et al. Cost-effectiveness of housing first intervention with intensive case management compared with treatment as usual for homeless adults with mental illness: secondary analysis of a randomized controlled trial. JAMA Netw Open. 2019;2(8):e199782.

27. Upshur CC, Jenkins D, Weinreb L, et al. Homeless women's service use, barriers, and motivation for participating in substance use treatment. Am J Drug Alcohol Abuse. 2018;44:252-62.

28. Tsemberis S, Gulcur L, Nakae M. Housing First, consumer choice, and harm reduction for homeless individuals with a dual diagnosis. Am J Public Health. 2004;94:651-6.

29. Falloon IR, Coverdale JH, Laidlaw TM, et al. Early intervention for schizophrenic disorders. Implementing optimal treatment strategies in routine clinical services. OTP Collaborative Group. Br J Psychiatry Suppl. 1998;172:33-8.

30. Senn CY, Eliasziw M, Barata PC, et al. Efficacy of a sexual assault resistance program for university women. N Engl J Med. 2015;372: 2326-35.

31. Bespalova N, Morgan J, Coverdale J. A pathway to freedom: an evaluation of screening tools for the identification of trafficking victims. Acad Psychiatry. 2016;40:124-8.
32. Ades V, Wu SX, Rabinowitz E, et al. An integrated, traumainformed care model for female survivors of sexual violence: the Engage, Motivate, Protect, Organize, Self-Worth, Educate, Respect (EMPOWER) Clinic. Obstet Gynecol. 2019;133:803-9.

33. Welch J, Mason F. Rape and sexual assault. BMJ. 2007;334:11548.

34. Linden JA. Clinical practice. Care of the adult patient after sexual assault. N Engl J Med. 2011;365:834-41.

35. Örmon K, Sunnqvist C, Bahtsevani C, Levander MT. Disclosure of abuse among female patients within general psychiatric care - a cross sectional study. BMC Psychiatry. 2016;16:79.

36. Rose D, Trevillion K, Woodall A, et al. Barriers and facilitators of disclosures of domestic violence by mental health services users: qualitative study. Br J Psychiatry. 2011;198:189-94.

37. Coverdale J, Falloon I, Turbott S. Sexually transmitted disease and family planning counselling of psychiatric patients in New Zealand. Aust N Z J Psychiatry. 1997;31:285-90.

38. Read J, Sampson M, Critchley C. Are mental health services getting better at responding to abuse, assault and neglect? Acta Psychiatr Scand. 2016;134:287-94.

39. Roebuck S. A letter to the man who tried to rape me. Medium.com, December 13, 2016. Available at https://medium.com/humandevelopment-project/a-letter-to-the-man-who-tried-to-rape-me3a18c17d8eb9. Last accessed 16 June 2019.

40. Campbell R, Raja S. Secondary victimization of rape victims: insights from mental health professionals who treat survivors of violence. Violence Vict. 1999;14:261-75.

41. Hensel JM, Ruiz C, Finney C, Dewa CS. Meta-analysis of risk factors for secondary traumatic stress in therapeutic work with trauma victims. J Trauma Stress. 2015;28:83-91.

42. Panagioti M, Panagopoulou E, Bower P, et al. Controlled interventions to reduce burnout in physicians: a systematic review and metaanalysis. JAMA Intern Med. 2017;177:195-205.

43. Shanafelt T, Goh J, Sinsky C. The business case for investing in physician well-being. JAMA Intern Med. 2017;177:1826-32.

Publisher's Note Springer Nature remains neutral with regard to jurisdictional claims in published maps and institutional affiliations. 